\title{
PENYELESAIAN CLEARANCE DENGAN SISTEM INAPORTNET GUNA MEMPERLANCAR ESTIMATED TIME DEPARTURE
}

\author{
Vega F. Andromeda \\ Politeknik Ilmu Pelayaran (PIP) Semarang \\ Jln. Singosari 2A \\ Semarang \\ www.vegameida@pip-semarang.ac.id
}

\author{
I Made Wahyu S. Putra \\ Politeknik Ilmu Pelayaran (PIP) Semarang \\ Jln. Singosari 2A \\ Semarang
}

\begin{abstract}
There is still a delay time of up to $86 \%$ and utilization of the pier that has not been optimal causing inefficiency in ports in Indonesia. Idle time that occurs at the port is due to the slow processing of ships and goods documents. The implementation of the Inaportnet system is expected to accelerate clearance completion in an effort to expedite the Estimated Time of Departure. This research was conducted at PT Dharma Lautan Utama Tanjung Perak Surabaya Branch using a descriptive qualitative research method. The results showed that the process of completing ship clearance at PT Dharma Lautan Utama Surabaya Branch has changed using the online system or using the Inaportnet system, but this system is still constrained by inadequate internet connections. The number of vessel documents that must be completed, the checking system for expired date of ship certificates is still manual, the ups and downs, and the length of time waiting for the cargo to arrive at the port also causes the length of the clearance process at Tanjung Perak Port.
\end{abstract}

Keywords: delay time; clearance; Inaportnet system; Estimated Time of Departure; ship.

\begin{abstract}
Abstrak
Masih adanya delay time hingga $86 \%$ serta belum optimalnya utilisasi dermaga yang belum optimal menyebabkan ketidakefisienan pelabuhan di Indonesia. Idle time yang terjadi di pelabuhan disebabkan karena waktu pengurusan dokumen kapal dan barang yang masih lambat. Penerapan sistem Inaportnet diharapkan dapat mempercepat penyelesaian clearance dalam upaya memperlancar Estimated Time of Departure. Penelitian ini dilaksanakan pada PT Dharma Lautan Utama Cabang Tanjung Perak Surabaya menggunakan metode penelitian deskriptif kualitatif. Hasil penelitian menunjukkan bahwa proses penyelesaian clearance kapal pada PT Dharma Lautan Utama Cabang Surabaya telah berubah menggunakan sistem online atau menggunakan sistem Inaportnet, tetapi sistem ini masih terkendala oleh koneksi internet yang kurang memadai. Banyaknya dokumen kapal yang harus diselesaikan, sistem pengecekan expired date sertifikat kapal masih manual, terjadinya pasang surut, dan lamanya menunggu muatan tiba pelabuhan juga menyebabkan lamanya proses clearance di Pelabuhan Tanjung Perak.
\end{abstract}

Kata-kata kunci: delay time; clearance; sistem Inaportnet; Estimated Time of Departure; kapal.

\section{PENDAHULUAN}

Saat ini kebutuhan akan sarana transportasi semakin besar, khususnya transportasi barang, baik untuk keperluan destinasi antarpulau maupun antarnegara (ekspor/impor). Kapal sebagai salah satu sarana jasa transportasi laut menjadi pilihan yang tepat untuk membawa barang atau muatan dalam jumlah yang besar (Burns, 2015). Industri maritim tidak lagi 
dipandang hanya sebagai alat untuk pengiriman, namun juga sudah dipandang sebagai salah satu pemain penting dalam pembangunan kota, daerah, dan perekonomian negara (Hall dan Jacobs, 2012; Song dan Panayides, 2012).

Tendensi tersebut terjadi berdasarkan pertimbangan finansial dan ekonomi, karena kapal lebih efektif dan lebih efisien jika dibandingkan dengan sarana transportasi lainnya. Dengan menggunakan kapal, biaya yang dikeluarkan lebih kecil jika dibandingkan dengan alat angkut lainnya (Christopher, 2016). Selain itu, jumlah muatan yang diangkut lebih besar dan waktu yang diperlukan untuk sampai pada tempat tujuan juga relatif cepat (Arianto, 2011; The Lloyd's Maritime Institute, 2018a).

Sistem manajemen pelabuhan perlu didukung oleh sistem informasi yang modern sehingga diharapkan pelabuhan memiliki kinerja yang efektif dan efisien, meningkatkan pertumbuhan ekonomi, dan menurunkan biaya logistik nasional (Sutejo, 2016; The Lloyd's Maritime Institute. 2018a; The Lloyd's Maritime Institute. 2018b). Pelabuhan di Indonesia dinilai masih belum efisien karena masih terjadi delay time hingga $86 \%$, dan belum optimalnya utilisasi dermaga (Sitorus et al., 2016). Salah satu faktor yang menyebabkan tingginya idle time di pelabuhan adalah lamanya waktu pengurusan dokumen kapal dan barang (Kurniawan et al., 2015).

PT Dharma Lautan Utama adalah sebuah perusahaan pelayaran niaga nasional yang menyediakan jasa kapal penyeberangan (ferry), yang meliputi angkutan penumpang dan muatan barang antarpulau, dan sangat mengedepankan manajemen dan kinerja tata laksana yang lebih efisien. Keutamaan itu diterapkan mulai dari awal rencana kedatangan kapal (arrival), pada saat kapal berada di pelabuhan, hingga waktu keberangkatan (departure). Setiap kegiatan pelayanan kapal penumpang tidak boleh mengabaikan rencana penanganan kapal secara menyeluruh, baik sejak penyandaran sampai keberangkatan kapal.

Rangkaian kegiatan penanganan kedatangan atau keberangkatan kapal meliputi pemberitahuan tentang rencana kedatangan dan keberangkatan kapal, penentuan dermaga, pelaksanaan kapal sandar dan berangkat, permintaan kebutuhan kapal, naik turunnya penumpang, serta pengurusan dokumen clearance in dan clearance out kapal kepada pihak atau instansi terkait. Kelancaran proses penyelesaian seluruh urusan operasional tersebut sangat menentukan kecepatan dan ketepatan waktu keberangkatan kapal. Apabila tahaptahap itu terhambat, kapal akan mengalami penundaan jadwal operasional (delay).

Salah satu penyebab masih adanya delay time pada keberangkatan kapal adalah pada tahap pelaksanaan clearance. Proses penyelesaian clearance in maupun clearance out belum dilaksanakan secara efektif dan efisien, sehingga berakibat pada keterlambatan Estimated Time of Departure (ETD). Sebagai contoh, pada bulan Maret 2019, sejumlah kapal yang berafiliasi pada PT Dharma Lautan Utama masih mengalami delay, karena dermaga yang melakukan kegiatan clearance kapal menghabiskan waktu yang lebih daripada yang diperkirakan. Hal tersebut dapat dilihat pada Tabel 1.

Delay kapal tidak hanya berdampak kepada ketidakpuasan pengguna jasa layanan kapal. Apabila terjadi delay, para pemilik kapal (principal) juga dikenai kewajiban membayar 
denda (penalty) berupa uang lebih demi kepentingan pengurusan dokumen administratif kapal di suatu pelabuhan. Penyelesaian kelengkapan dokumen kapal ini bersifat niscaya, karena tanpa hal itu sebuah kapal tidak diizinkan untuk berlayar atau mengerjakan suatu aktivitas (Conceicao, 2017).

Tabel 1 Data Delay Kapal Milik PT Dharma Lautan Utama

\begin{tabular}{cccccc}
\hline No. & Nama Kapal & ETA & ETD & Time Departure & Keterangan \\
\hline 1 & Dharma Rucitra VII & $18 / 03 / 2019$ & $18 / 03 / 2019$ & $19 / 03 / 2019$ & Delay 2 Jam \\
& & $06: 40$ & $24: 00$ & $02: 30$ & 30 menit \\
2 & Dharma Kartika IX & $23 / 03 / 2019$ & $24 / 03 / 2019$ & $24 / 03 / 2019$ & Delay 1 Jam \\
& & $22: 45$ & $02: 00$ & $03: 25$ & 30 menit \\
3 & Dharma Rucitra VII & $25 / 04 / 2019$ & $25 / 04 / 2019$ & $25 / 04 / 2019$ & Delay 1 Jam \\
& & $12: 50$ & $17: 55$ & $19: 00$ & 5 menit \\
4 & Satya Kencana III & $25 / 05 / 2019$ & $26 / 05 / 2019$ & $26 / 05 / 2019$ & Delay 1 Jam \\
& & $11: 15$ & $06: 55$ & $08: 00$ & 5 menit \\
\hline
\end{tabular}

Salah satu solusi yang ditempuh untuk meningkatkan efisiensi pelayanan jasa kapal dan mengatasi masalah delay kapal adalah mengubah metode penyelesaian dokumen kapal dari cara manual menjadi sistem online (Panayides dan Song, 2015). Penggunaan sistem online diharapkan dapat meningkatkan kecepatan, kredibilitas, dan transparansi standar pelayanan kapal agar biaya penanganan kapal di pelabuhan semakin minim. Kinerja penanganan atas kegiatan perdagangan dan lalu lintas barang pun semakin bermutu, terutama dalam hal memperlancar ETD. Akan tetapi, berdasarkan fakta yang ada, solusi perubahan tersebut belum luput dari persoalan. Prosedur penyelesaian dokumen yang menggunakan sistem online, yang mana tidak ada tatap muka langsung antara pihak pengguna jasa dengan pihak pemberi perizinan, justru berdampak pada lambatnya perizinan yang diberikan (Saifudin, 2009).

Masalah teknis banyak dihadapi dalam hal penggunaan sistem online. Sebagai contoh, tingginya frekuensi pengguna internet menyebabkan koneksi internet menjadi buruk, yang menyebabkan proses port clearance terhambat. Selain itu, dalam proses pemuatan (upload) dokumen-dokumen kapal ke dalam sistem Inaportnet, ukuran file dokumen-dokumen kapal seringkali cukup besar, sehingga waktu pemuatan (upload) dokumen-dokumen kapal tersebut ke dalam sistem Inaportnet lebih lama. Karena itu, petugas pun dipaksa untuk menyediakan waktu ekstra guna memperkecil ukuran-ukuran file yang telah dipindai (scan). Proses ini terkadang menyebabkan permohonan izin kapal ditolak oleh sistem. Adanya proses tunggu muatan (waiting charge) juga menyebabkan terhambatnya kelancaran kegiatan operasional dalam penyelesaian dokumen kapal.

Permasalahan dalam tata laksana penanganan kapal, khususnya yang terjadi di PT Dharma Lautan Utama Cabang Surabaya, tentu perlu ditangani. Masalah tersebut sangat memengaruhi mutu pelayanan dan efisiensi kinerja perusahaan pelayaran tersebut. Tujuan penelitian adalah untuk menelusuri lebih dalam proses menyeluruh penanganan kedatangan dan keberangkatan kapal yang berlangsung di PT Dharma Lautan Utama Cabang Surabaya 
dan menggali faktor-faktor yang menghambat proses clearance sebagai salah satu bagian pentingnya, terutama kendala dalam penyelesaian clearance secara online.

\section{METODE PENELITIAN}

Pengumpulan data dilakukan di PT Dharma Lautan Utama Cabang Tanjung Perak pada bulan Juni 2019 dengan cara observasi, studi dokumentasi, dan wawancara. Pada studi ini wawancara dibagi menjadi 2 jenis wawancara, yaitu: (1) wawancara mendalam (in-depth interview), dengan tanya jawab dilakukan tanpa menggunakan pedoman yang disiapkan sebelumnya serta dilakukan berulang, dan (2) wawancara terarah (guide interview), dengan pertanyaan-pertanyaan yang diajukan menggunakan pedoman yang telah disiapkan sebelumnya. Responden yang diharapkan adalah pembimbing prada, kepala-kepala bagian, karyawan atau pegawai pada PT Dharma Lautan Utama Cabang Surabaya.

Analisis data dilakukan dengan pendekatan deskriptif kualititaf untuk mengetahui kendala-kendala dalam penyelesaian clereance dengan sistem Inaportnet dalam kaitannya memperlancar ETD di PT Dharma Lautan Utama Cabang Surabaya. Validitas keabsahan data diperiksa dengan menggunakan triangulasi. Triangulasi dilakukan dengan cara mengecek data kepada sumber yang sama dengan teknik yang berbeda. Selain dengan wawancara, data pada studi ini juga dicari melalui observasi. Bila terdapat perbedaan data, dilakukan pengolahan data kembali untuk memastikan data yang valid.

\section{HASIL DAN PEMBAHASAN}

Penggunaan sistem Inaportnet dinilai belum sepenuhnya optimal karena dalam pelaksanaannya masih ditemukan kendala-kendala teknis. Pada saat ini, proses penyelesaian clearance kapal telah mengalami perubahan, dari yang awalnya menggunakan sistem manual menjadi sistem online dengan sistem Inaportnet. Pengguna sistem Inaportnet adalah instansi pemerintah dan badan usaha pelabuhan serta pelaku industri logistik di Indonesia yang memanfaatkan jasa kepelabuhanan, seperti shipping lines/agent, freight forwarder, ontainer Freight Station (CFS), Custom brokerage (PPJK), importir dan eksportir, depo container, warehouse, dan inland transportation (Malisan dan Trisnawati, 2019). Tahap pelaksanaan proses penyelesaian clearance kapal menggunakan sistem Inaportnet diuraikan lebih detail pada bagian berikut.

\section{Proses Clearance In Kapal}

Dalam hal ini agen PT Dharma Lautan Utama Cabang Surabaya mempunyai banyak tugas dan tanggung jawab mengenai kapal, mulai dari kapal akan memasuki area pelabuhan, 
melakukan kegiatan bongkar muat, sampai kapal tersebut meninggalkan Pelabuhan Tanjung Perak.

1) Hal-hal yang perlu dipersiapkan sebelum kapal datang adalah sebagai berikut:

a) Agen selalu memantau berita kapal selama perjalanan dan melakukan kontak ke pihak kapal, khususnya dengan Captain Kapal, untuk mengirimkan Master Cable untuk mengetahui jadwal kapal akan tiba. Untuk proses clearance in agen mengajukan layanan kedatangan kapal dalam waktu paling lambat 1 × 24 jam, dan terlebih dahulu agen harus mendaftarkan kapal dengan mengajukan penunjukan keagenan ke sistem (Inaportnet) untuk diverifikasi oleh Penyelenggara Pelabuhan (Otoritas Pelabuhan) sehingga status layanan keagenan tadi berubah menjadi warta kapal.

b) Agen melengkapi data pada warta kapal tersebut dengan selengkap-lengkapnya dan selanjutnya warta dikirim ke Penyelenggara Pelabuhan dalam bentuk PKK dan ke Syahbandar dalam bentuk SPM. Dalam proses verifikasi oleh masing-masing instansi, batas waktu untuk memberikan respons ke Inaportnet adalah 5 jam sejak layanan diterima.

c) Setelah PKK dan SPM disetujui PKK yang telah diverifikasi oleh Penyelenggara Pelabuhan, BUP mengirimkan data RPK-RO ke Penyelenggara Pelabuhan dari PPKB yang diajukan sebagian datanya dari PKK yang telah diverifikasi. Data yang masuk ke Penyelenggara Pelabuhan dalam bentuk layanan PPK adalah untuk penyandaran kapal. Penerbitan SPK Pandu dari BUP, apabila PPK telah ditetapkan oleh Penyelenggara Pelabuhan, SPOG dapat diterbitkan paling lambat 1 jam sejak SPK pandu diterbitkan. Setelah SPK Pandu diterbitkan, kapal bisa langsung menghubungi pihak kepanduan untuk pandu sandarnya kapal. Kegiatan agen setelah data Inaportnet diverifikasi sebagai berikut:

(1) Mengadakan pra-meeting di Pusat Pelayanan Satu Atap (PPSA) untuk menentukan jam pemanduan dan lama tambat.

(2) Mengadakan meeting penetapan sandar di Kesyahbandaran dan Otoritas Pelabuhan (KSOP) dan Agen itu sendiri untuk laporan kapal untuk pergerakan.

(3) Agen memberikan informasi ke karantina untuk kedatangan kapal, untuk kemudian diperiksa dan untuk proses penerbitan Port Health Quarantine Clearance (PHQC) dengan melampirkan Crew List. Dokumen untuk keperluan clearance in kapal diperuntukkan untuk arsip agen perusahaan, PELINDO, arsip Kesyahbandaran, dan bagian Lalu Lintas Laut (LALA) Otoritas Pelabuhan dengan melampirkan Rencana Pola Trayek (RPT), Penunjukan Keagenan, Crew List, Ship Particular, Surat Laut, Surat Ukur, Surat Persetujuan Berlayar (SPB) kedatangan, Laporan Kedatangan Kapal (LKK), dan Surat Persetujuan Olah Gerak (SPOG). Setelah semua kelengkapan clearance in selesai diperiksa, agen memberikan informasi kepada Master untuk siap-siap melakukan pergerakan. 
2) Pada saat kapal tiba, yang dilakukan oleh agen pada PT Dharma Lautan Utama Cabang Surabaya adalah sebagai berikut:

a) Setelah kapal sandar, agen mengambil dokumen-dokumen lain untuk dilakukan memorandum dan proses clearance in dan clearance out. Sebelum dokumen dibawa ke syahbandar, agen memeriksa dokumen terlebih dahulu, apakah ada dokumen yang expired atau tidak valid (Memorandum). Bila terdapat dokumen yang expired, agen akan melaporkan dan membuat surat pembaharuan dokumen yang expired tersebut kepada pihak KSOP. Selama kapal berada di pelabuhan, dokumen-dokumen kapal tetap disimpan di syahbandar sampai kapal akan meninggalkan pelabuhan tersebut.

b) Agen melakukan Clearance Health Book, SSCEC, P3K ke karantina untuk pemeriksaan kapal dan pengajuan penerbitan PHQC. Untuk Clearance Quarantine ke Dinas Kesehatan Pelabuhan mengenai Sanitasi kapal dengan melampirkan: Health Book, Ships Sanitation Control Exemption Certificate (SSCEC), mengajukan permohonan Clearance, dan Daftar Crew List.

\section{Proses Clearance Out Kapal}

Setelah kapal selesai melakukan kegiatan di pelabuhan dan akan kembali lagi berlayar keluar dari wilayah pelabuhan, agen melakukan kembali permohonan keberangkatan kapal atau clearance out. Proses Clearance Out sebagai berikut:

1) Pengecekan dokumen terlebih dahulu dan dalam waktu paling dalam 6 jam sebelum kapal keluar agen mengajukan layanan kapal keluar di sistem Inaportnet yang datanya masuk ke Penyelenggara Pelabuhan (OP), beberapa LKK, dan LK3. Sebelumnya agen membuat warta keberangkatan, yang berisi Data Manifes Kapal Muat, Data Awak Kapal, Dokumen Kapal, dan Pandu Keluar. Setelah semua warta kapal diisi dengan lengkap dan benar, agen mengirimkan ke SIMLALA untuk kemudian diverifikasi apakah ada revisi atau sudah benar. LKK yang telah diverifikasi oleh Penyelenggara Pelabuhan akan secara otomatis direspons oleh SIMPONI untuk penerbitan kode billing yang selanjutnya agen melakukan pembayaran PNPB Labuh dari kode billing yang didapat. Apabila telah dilunasi oleh agen, secara otomatis LK3 sudah bisa dilakukan verifikasi dan data bisa masuk ke Syahbandar sehingga bisa melakukan verifikasi data agar SPB terbit. Penerbitan SPK Pandu untuk kapal keluar paling lambat 1 jam sejak Surat Persetujuan Berlayar (SPB) diterbitkan. Penerbitan SPOG paling lambat 1 jam sejak SPK Pandu diterbitkan. Untuk keperluan clearance out untuk kapal, dokumen diperuntukkan untuk arsip agen perusahaan, arsip Adpel, dan bagian Lalu Lintas Laut (LALA) KSOP Tanjung Perak dengan melampirkan Laporan Kedatangan dan Keberangkatan Kapal (LKK), Bukti PUP Labuh, Bukti PUP Rambu, Bukti PUP VTS, Crew List, Memorandum, Manifes Muat, Master Sailing Declaration (Surat Pernyataan Nakhoda). Dalam waktu 1 x 24 jam agen melakukan pemberitahuan keberangkatan kapal kepada KSOP, Pelindo III Surabaya, dan memberikan arsip dokumen kapal. 
2) Setelah proses clearance SPB selesai dan semua administrasi keperluan kapal sudah dibayar, agen membuat warta kapal order ke Pandu Labuh dan Tambat untuk kepastian keberangkatan kapal, dan setelah On Board kapal berangkat melanjutkan pelayaran ke pelabuhan berikutnya. Jangka waktu berlakunya SPB di pelabuhan sebelum bertolak ke pelabuhan berikutnya adalah $1 \times 24$ jam.

3) Setelah semua dokumen clear dan dokumen selesai diperiksa, agen membawa kembali dokumen ke atas kapal untuk diserahkan ke nakhoda dan dokumen kapal diperiksa kembali oleh nakhoda.

Hambatan-hambatan yang terjadi dalam pelaksanaan penyelesaian clearance kapal

PT Dharma Lautan Utama di Pelabuhan Tanjung Perak adalah sebagai berikut:

1) Jenis Dokumen Kapal

Sebelum penyelesaian dokumen kapal menggunakan sistem Inaportnet perlu diperiksa dan diteliti masa berlaku semua sertifikat kapal, karena selain dokumen-dokumen kapal yang di-upload ke dalam sistem Inaportnet jumlahnya banyak, dan semua sertifikat kapal harus masih berlaku. Dalam penyelesaian dokumen kapal PT Dharma Lautan Utama Cabang Surabaya, pernah ditemukan adanya sertifikat kapal yang expired ketika kapal itu sedang berlayar atau ketika kapal sedang berada di tengah laut. Proses penyelesaian dokumen kapal menggunakan sistem Inaportnet untuk keberangkatan kapal tidak efektif dan tidak efisien dikarenakan agen harus melakukan perpanjangan sertifikat yang expired tersebut. Pada umumnya penyelesaian dokumen kapal menggunakan sistem Inaportnet akan berjalan dengan efektif dan efisien apabila semua persyaratan keselamatan dan keamanan pelayaran dipenuhi, seperti masih berlakunya sertifikat kapal.

2) Koneksi Internet

Koneksi internet yang buruk dapat berdampak pada kinerja pihak agen, yang terhambat dalam proses upload dokumen-dokumen kapal ke dalam sistem Inaportnet, sehingga tidak efisiennya waktu karena lambatnya koneksi internet, yang mengakibatkan verifikasi dari instansi-instansi terkait juga menjadi semakin lama. Kelemahan sistem Inaportnet adalah bila ada permasalahan dengan internet, harus menunggu selesai perbaikan atau dilakukan secara manual sesuai perintah dari Otoritas Pelabuhan dan Pelindo. Dalam hal ini yang dirugikan adalah agen/pengguna jasa, karena kapal akan mengalami delay yang lebih lama dan akhirnya terjadi keterlambatan kedatangannya di pelabuhan tujuan.

3) Kapasitas ukuran file dokumen kapal yang besar

Bila ada dokumen dengan ukuran yang terlalu besar, dokumen tersebut tidak bisa diterima oleh sistem, sehingga permohonan di sistem Inaportnet bisa ditolak atau dokumen tersebut harus direvisi terlebih dahulu, karena data yang akan di-upload harus berupa file yang ukurannya kecil (tidak lebih dari $1 \mathrm{MB}$ ). 
Upaya yang dilakukan untuk menyelesaikan masalah Inaportnet adalah:

1) Agen segera berkoordinasi dengan instansi-instansi terkait ketika koneksi internet buruk atau sistem Inaportnet mengalami gangguan.

2) Agen segera memperkecil ukuran file dokumen-dokumen kapal ketika dokumendokumen kapal telah selesai di-scan, kemudian mengarsipkan file dokumen-dokumen kapal tersebut ke dalam satu folder, sehingga dapat memudahkan agen dalam proses penyelesaian atau peng-upload-an dokumen-dokumen atau sertifikat kapal ke dalam sistem Inaportnet.

3) Perusahaan diharapkan dapat memperbaiki pengendalian internal perusahaan dalam kegiatan penyelesaian dokumen kapal menggunakan sistem Inaportnet dengan cara menggunakan aplikasi sederhana reminder sertifikat kapal. Dengan aplikasi ini, agen tidak perlu mengecek expired date sertifikat kapal secara manual.

\section{KESIMPULAN}

Proses penyelesaian clearance kapal pada PT Dharma Lautan Utama Cabang Surabaya telah berubah dari sistem manual menjadi sistem online atau menggunakan Inaportnet. Penyelesaian clearance kapal menggunakan sistem Inaportnet melalui beberapa tahap yakni, persiapan, proses clearance in, mulai dari sebelum kapal datang dan pada saat kapal sandar di pelabuhan, dan proses clearance out.

Agen mengajukan layanan kapal keluar melalui sistem Inaportnet dengan mengupload data agar bisa diakses oleh penyelenggara pelabuhan (Otoritas Pelabuhan), Pelindo, beberapa LKK, dan LK3. Setelah semua dokumen clear dan dokumen selesai diperiksa, agen membawa kembali dokumen ke atas kapal untuk diserahkan kepada nakhoda dan dokumen kapal diperiksa kembali oleh nakhoda.

Hambatan-hambatan yang terjadi dalam proses penyelesaian clearance kapal menggunakan sistem Inaportnet, antara lain, adalah banyaknya dokumen kapal yang harus diupload, koneksi internet yang belum mendukung sistem Inaportnet, proses pengecekan expired date sertifikat kapal masih manual, kondisi pasang surut air laut yang menyebabkan kapal tidak bisa langsung sandar, dan lamanya muatan tiba di pelabuhan. Proses penyelesaian clearance kapal dengan sistem Inaportnet memberikan kemudahan bagi perusahaan atau agen dan para pengguna jasa.

Sistem Inaportnet dapat mempermudah dan memberikan layanan kepada pengguna jasa. Selain itu, sistem Inaportnet dapat mengefisiensikan waktu penyelesaian clearance kapal dalam memperlancar Estimated Time of Departure (ETD) kapal, sehingga kapal terhindar dari delay yang dapat merugikan pihak kapal. 


\section{UCAPAN TERIMAKASIH}

Terimakasih disampaikan kepada seluruh pihak yang terlibat dalam riset ini. Secara khusus ucapan terima kasih juga disampaikan kepada semua jajaran pengurus PT Dharma Lautan Utama Cabang Surabaya atas semua informasi, pelayanan, dan sumbangsih dalam mendukung penelitian ini.

\section{DAFTAR PUSTAKA}

Arianto, D. 2011. Kajian Penyebab Non-Aktif Kegiatan Bongkar Muat di Pelabuhan dan Dampaknya terhadap Biaya Demurrage. Jurnal Penelitian Transportasi Laut, 13 (3): 173-181.

Burns, M.G. 2015. Port Management and Operation. New York, NY: CRC Press.

Christopher, M. 2016. Logistics and Supply Chain Management. Fifth Edition. London: Pearson Education.

Conceicao, B.D. 2017. Proses Penyelesaian Dokumen Kedatangan dan Keberangkatan Kapal Penumpang pada PT Pelayaran Nasional Indonesia (Persero) Cabang Ende Data PT Dharma Lautan Utama Cabang Surabaya Tahun 2019. Surabaya.

Hall, P.V. dan Jacobs, W. 2012. Why are Maritime Ports (Still) Urban, and Why Should Policymakers Care? Maritime Policy and Management, 39 (2): 189-206.

Kurniawan, A., Seminar, K.B., Iskandar, B.H., dan Nasution, S. 2015. Studi Kelayakan Inaportnet dan Strategi Pengembangan e-business di Pelabuhan Makassar. Warta Penelitian Perhubungan, 27 (5): 345-356.

Malisan, J. dan Trisnawati, W. 2019. Implementasi Inaportnet dalam Pelayanan Terpadu Satu Pintu di Pelabuhan Tanjung Perak Surabaya. Warta Penelitian Perhubungan, 31 (2): 67-74.

Panayides, P.M. dan Song, D.W. 2015. Maritime Logistics: A Guide to Contemporary Shipping and Port Management. New York, NY: Kogan Page.

Saifudin. 2009. Analisis Kesiapan Penerapan Inaport Integration System (Inaportnet) pada Pelayanan Kapal di Pelabuhan Tanjung Priok. Skripsi tidak diterbitkan. Depok: Program Studi Teknik Perkapalan, Universitas Indonesia.

Sitorus, B., Sitorus, T. I. H., dan Ricardianto, P. 2016. Evaluasi Manajemen Sistem Informasi dan Teknologi Informasi Pelabuhan. Jurnal Manajemen Transportasi dan Logistik (JMTransLog), 3 (3): 367-378.

Song, D.W. dan Panayides, P.M. 2012. Maritime Logistics: A Complete Guide to Effective Shipping and Port Management. New York, NY: Kogan Pae.

Sutejo, A.B. 2016. Rancang Bangun Sistem Informasi Pelabuhan Perikanan: Studi Kasus di Pelabuhan Perikanan Samudera Cilacap. Bogor: IPB Scientific Repository. 
The Lloyd's Maritime Institute. 2018a. Shipping Operations and Port Management.Course Module. Portland, OR.

The Lloyd's Maritime Institute. 2018b. Logistic and Shipping Management. Course Module. Portland, OR. 